\title{
Gestión de núcleos investigativos: Caso de la Universidad de Antofagasta de Chile*
}

\author{
Ganga Contreras, Francisco** \\ Villegas Villegas, Francisco*** \\ Uriola López, Kattherinne $e^{* * * *}$ \\ Tapia Henríquez, Mario ${ }^{* * * *}$
}

\section{Resumen}

La producción de nuevos saberes es una de las funciones cardinales de toda universidad compleja o que aspire decididamente a tal condición; por lo mismo, estas entidades educativas deben ser capaces de desarrollar estrategias tendientes a aportar en esta perspectiva. Considerando este breve exordio contextual, este trabajo tiene como finalidad primordial exponer los primeros avances respecto de la experiencia en la gestión de los núcleos investigativos en docencia universitaria y su efecto en la gestación de nuevo conocimiento, en una universidad del Estado de Chile. Metodológicamente hablando, se trata de un estudio que recoge evidencia tanto cuantitativa como cualitativa, la que ha sido orientada a comprender las dinámicas que se han dado en la puesta en práctica

\section{Recibido: 15-03-16. Aceptado: 18-07-16}

* Se agradece a todos los académicos y profesionales que participaron de la experiencia de Núcleos de Investigación entre los años 2014 y 2015 en la Universidad de Antofagasta. De igual forma, al equipo directivo de la Universidad de Antofagasta, encabezados por su rector Dr. Luis Loyola Morales, el Vicerrector Académico de la época Sr. Hernán Sagua Franco y la Directora de la Unidad de Gestión Académica, Mg. Claudia Valderrama Hidalgo.

** Administrador Público, Licenciado en Administración, Magíster en Administración de Empresas, DEA en Organización de Empresas, Doctorado en Administración de Empresas y Postdoctorado en Ciencias Humanas. Actualmente es Profesor Titular A del Departamento de Ciencias del Desarrollo de la Universidad de Los Lagos-Chile. Correo postal: República Nº 517, Universidad de Los Lagos, Chile. e-mail: fganga@ulagos.cl

*** Profesor de Enseñanza Media en Castellano, Magister en Educación, UMCE, Máster en Didáctica de la Lengua y la Literatura, Universidad de Barcelona; candidato a Doctor en Didáctica por la Universidad de Barcelona. Coordinador de Núcleos de Investigación en Docencia de la Universidad de Antofagasta. e-mail: francisco.villegas@uantof.cl

**** Profesora de Español, Doctora por la Universidad de Barcelona, Asesora Área de Evaluación y Monitoreo en la Vicerrectoría Académica de la Universidad de Antofagasta.e-mail: kettherinne.urriola@uantof.cl

***** Profesor de Español. Doctor por la Universidad de Barcelona, Asesor de rediseño curricular de la Facultad de Ingeniería. e-mail: mario.tapia@uantof.cl 
de esta estrategia, tendiente a generar nuevos conocimientos, factibles de ser publicados en revistas académicas indexadas. En su primera versión 2014, esta iniciativa abarcó a un total de 31 convocados, generando 30 artículos; y para la versión 2015-2016, la actividad ha ampliado su cobertura a más de noventa participantes, lográndose 38 nuevos documentos.

Palabras clave: Investigación educativa; innovación; docencia universitaria; reflexión acción; gestión de la calidad; gestión universitaria; política institucional.

\section{Management of Research Centers: Case of the University of Antofagasta of Chile}

\section{Abstract}

The production of new knowledge is one of the cardinal functions of any complex university, or any university that wants to be complex; therefore, these educational institutions should be able to develop strategies to contribute to this complexity. Considering this brief contextual preamble, this work is intended primarily as exposing the first progresses about the experience on managing research centers in university teaching and its effect in the creation of new knowledge, in an university of the State of Chile. Methodologically speaking, it is about a case of study that includes both quantitative and qualitative evidence, which has been oriented to understand the dynamics that have occurred in the implementation of this strategy, aimed at generating new knowledge, feasible to be published in refereed academic journals. In its first version in 2014, this initiative covered a total of thirty-one people summoned and, for its version from 2015 to 2016, the activity has expanded its coverage to more than ninety participants and generated 38 new documents.

Key words: Teaching research; innovation; university teaching; reflection action; quality management; university management; institutional policy.

\section{Introducción}

La docencia en la Universidad de Antofagasta $^{1}$ constituye el centro del quehacer académico que reconoce en la extensión del conocimiento una labor vinculada directamente con los estudiantes y con los profesores que ejercen la labor pedagógica. Como parte de esa actividad central se encuentra la investigación en tanto generación de conocimiento la cual, en la Universidad de Antofagasta, centra su foco en un estudio, que va desde el periodo 2014-2015, en los docentes que tienen producción científica inicial o bien en aquellos que realizan estudios emergentes en sus contextos disciplinarios y de gestión pedagógica. En este sentido, en la literatura especializada, se encuentran variadas dimensiones que relacionan el desempeño docente con el énfasis por generar investigación y asociarla con los proce-

La Universidad de Antofagasta es una universidad pública y estatal fundada el 10 de marzo de 1981 perteneciente al Consejo de Rectores de las Universidades chilenas; fue derivada de la Universidad de Chile y la Universidad Técnica del Estado (UTE). Su casa central se encuentra, en la ciudad de Antofagasta, Chile, en el Campus Angamos. 
sos de enseñanza-aprendizaje en el nivel de educación superior (Díaz, 2005).

Lo anterior, está asociado a una promoción profesional en el sentido de que la docencia es una dimensión en el contexto universitario y que, ante los cambios de la profesión docente -más todavía en el ámbito de la investigación- planea una línea vectorial vinculada a profesionalizar el quehacer del docente universitario para acercarse a procesos de reflexión crítica, de indagación o de cuestionamiento asumiendo que el componente "profesorado académico" puede generar conocimiento disciplinario y pedagógico y por extensión, generar conocimiento e insumos pedagógicos válidos en el área de educación superior. En este sentido, lo que ha caracterizado a esta iniciativa, entendida como un programa formativo docente, es su ámbito colegiado, es decir, que quienes lo integran corresponden a una serie de académicos y profesionales provenientes de diversas unidades, lo que posibilita potenciar un trabajo colaborativo bajo una mirada de acción interdisciplinaria.

En este sentido, se puede afirmar que el propósito cardinal de este trabajo, está orientado a presentar descriptivamente los avances de la experiencia desarrollada en una universidad estatal del norte chileno, respecto de la planificación y gestión de los núcleos investigativos en docencia universitaria y su efecto en la generación de nuevo conocimiento.
En este contexto, la gestión en investigación es un área que se convierte en eje conceptual y estratégico de las universidades, que certifica la mejora en la docencia universitaria (Imbernon, 2012) al implicar, en la experiencia de la Universidad de Antofagasta, a la institucionalidad y al colectivo docente. En dicho proceso, la premisa considera un trabajo empírico en la perspectiva de un estudio de caso $^{2}$ el que consiste en el abordaje de lo específico y particular en el sentido de elegir un objeto para ser estudiado.

De esta manera, se operacionaliza una actividad en dos periodos temporales, a saber 2014 y 2015 , y se presentan resultados incrementales que seguirán en curso en la institución. Es así como esta exitosa estrategia de mejora viene a dar apoyo y a materializar parte de las políticas institucionales de dicha casa de estudios que persiguen reforzar la investigación en docencia. Dicha actividad, que en su primera versión abarcó a un total de treinta y un participantes y actualmente, su cobertura alcanza a más de noventa, se basa, principalmente, en la realización de grupos de trabajo colaborativo conformados por académicos motivados por dar a conocer sus trabajos de investigación en docencia, mediante la publicación de éstos en revistas indexadas y el apoyo sistemático, institucionalizado y escalado, materializado en la asesoría y seguimiento, por parte de profesionales afines,

2 El estudio de caso, según Stake (1994) no es la elección de un método sino más bien la elección de un objeto a ser estudiado. En tanto enfoque de investigación, un estudio de caso es definido por el interés en casos individuales antes que por los métodos de investigación utilizados. 
de los trabajos de investigación que dan vida a dichos núcleos.

Desde la óptica de los contenidos, en primera instancia se presenta un abordaje relacionado con la relevancia que debe tener la investigación para las universidades y el impacto que esta función tiene en los rankings internacionales; enseguida, se da paso a una revisión de los marcos de acción y a la situación actual de la investigación en la Universidad de Antofagasta; luego se entregan argumentaciones que sustentan la necesidad de realizar esta actividad en el ámbito de la docencia; para dar paso finalmente, a una exposición relacionada con la metodología utilizada y una presentación de los respectivos resultados.

\section{Importancia de la investigación en las universidades}

La investigación en el contexto de las universidades en América Latina aún se mantiene en el espacio de los países sub-desarrollados y será muy difícil que salga de esa condición, sino apuesta decididamente por invertir en investigación y desarrollo. En este sentido, y tal como se señala en el informe "Perspectivas económicas de América Latina 2015, Educación, competencias e innovación para el desarrollo" (OCDE, CEPAL, CAF, 2015: 14), el capital de innovación representa un indicador adicional de competencias que mide la capacidad para innovar y diseminar la innovación. El stock de capital de innovación es significativamente inferior en América Latina (13\% del PIB) que en los países de la OCDE $(30 \%$ del PIB). Además, en la región este activo se compone esencialmente del stock de educación terciaria, mientras en países de la OCDE se basa en el gasto en actividades de I+D.

Para salir de este abismo, se debe colaborar con diversas acciones desde todas las instituciones, teniendo un rol preponderante en este desafío, las respectivas universidades. Estas instituciones deben privilegiar la investigación y comprender que dicha tarea implica mejorar significativamente la calidad con la cual se transfiere el conocimiento, dado que posibilita un contacto con la realidad y con las nuevas tendencias que existen en las diversas áreas de desarrollo que tiene un país. Lo anterior, permite, a su vez, cuestionar las teorías existentes y formular nuevas ideas, incrementando la posibilidad de implementar nuevas soluciones a los problemas que impone la vida diaria.

Pero, como las instituciones la hacen las personas, colocar el énfasis en el rol que ellas deben cumplir en este campo, resulta ineluctable. En este sentido, Ander-Egg (2008: 129) indica que es impropio de un profesional no asumir una actitud científica en todas las circunstancias de la vida; actitud éticamente valiosa, pues da a los hombres una apertura espiritual e intelectual para un diálogo sin barreras de ninguna índole; porque hace flexible la mente de los hombres, capacitándolo para liberarse de todo aquello que verifican no ser verdadero, porque libera a los hombres de la enajenación del error y la ignorancia.

Ahora bien, si la anterior meditación es válida para un profesional, se torna un imperativo para el mundo universitario, pues en ellas deben estar todas 
aquellas personas inquietas intelectualmente, con capacidad para plantearse múltiples interrogantes del porqué ocurren los fenómenos y junto con hacerse preguntas, deben tener el talento suficiente para lograr respuestas a estos fenómenos. No es por lo tanto casualidad, que exista cierto consenso en señalar que una de las tareas centrales de la universidad debe ser la gestación de nuevos saberes que tengan utilidad en la vida individual y colectiva de los seres humanos.

En esta época, donde se transita por la sociedad de la información se ha llegado a señalar incluso, que el conocimiento y la información son, más que nunca, fuentes principales de riqueza, poder y calidad de vida en nuestro tipo de sociedad. En este sentido, la universidad, además de ser la principal organización generadora de conocimiento, es el actor central de los hallazgos y creaciones científicas e innovaciones tecnológicas sobre los que se basa el conjunto de procesos constitutivos de nuestras sociedades (Castells, 2012: 37).

Para enfrentar los desafíos de la generación del conocimiento, la institución universitaria debe recurrir a la denominada investigación científica. Como lo expresa de manera nítida el filósofo argentino Bunge (2007: 3), la investigación corrige o hasta rechaza porciones del acervo del conocimiento ordinario. La ciencia en resolución, crece a partir del conocimiento común y le rebasa con su crecimiento; de hecho, la investigación científica empieza en el lugar mismo en que la experiencia y el conocimiento ordinarios dejan de resolver problemas 0 hasta de plantearlos.
Complementariamente, mirado ahora desde la óptica etimológica, se dice que este concepto está referido a la acción de examinar sistemáticamente, observar, tratar de descubrir, de acuerdo al latín investigare "buscar cuidadosamente, seguir la pista, descubrir" (Gómez de Silva 2013: 387) lo que se puede complementar con la idea asociada a "vestigium", que implica seguir la huella. Se podría decir entonces que la sociedad espera que sean precisamente las universidades, las encargadas de seguir la huella a aquellos temas que le preocupan y sobre los cuales se necesitan respuestas.

Es decir, la búsqueda incesante de soluciones a las problemáticas, potencialmente se transformarán en nuevo conocimiento, emergiendo con ello una segunda gran responsabilidad: la correspondiente transferencia de los saberes que se han gestado, a la respectiva comunidad. Lo anterior, implica reconocer el rol de la investigación -no sólo como acicate de la reflexión crítica e innovativasino que también, en la formación de las personas, pero por, sobre todo, su papel trascendente y estratégico para el desarrollo de los países, dado que la búsqueda de la verdad, se transforma en información y ésta, a su vez, en conocimiento.

\section{La investigación y el impacto en los rankings de las universidades}

Los resultados de la globalización ha afectado a todas las organizaciones y las universidades no han quedado al margen de esta megatendencia, fenómeno que se ha transformado en un terreno fértil para la gestación de la competencia en 
las entidades de educación superior a nivel mundial y en una necesidad por saber los niveles de excelencia que tienen las universidades, lo cual ha posibilitado que surjan iniciativas tendientes a clasificarlas, logrando con ello, entregar información muy relevante para captar estudiantes, capturar fondos (especialmente para la investigación) y atraer el mejor capital humano disponible.

Por otra parte, la evolución de la enseñanza y de la investigación, hace necesario realizar una continua evaluación de las mismas, con el objetivo de proporcionar retroalimentación de los resultados obtenidos (Buela-Casal, QuevedoBlasco y Guillén-Riquelme, 2015: 317). Una opinión similar tiene Ordorika y Rodríguez (2010: 10), para quien la proliferación de rankings universitarios de alcance nacional, regional y mundial, se explica principalmente por la convergencia de distintas racionalidades. En primer lugar, el interés de los usuarios de servicios de educación superior: por un lado, los estudiantes y sus familias, que buscarían acceder a las mejores opciones educativas; por otro, los empleadores que utilizarían las mediciones de calidad de los programas como filtros para sus prácticas de selección de personal.

Este es el papel que cumplen los diversos rankings de universidades, tanto a nivel nacional como internacional, siendo la investigación uno de los factores determinantes en la posición que ocupan las instituciones de educación superior. En este orden de cosas, se utilizan una serie de indicadores, que implican considerar aspectos como: producción y productividad de artículos publicados, proyectos de investigación y desarrollo, doctorados acreditados, patentes, entre otros. Un ejemplo de estos elementos, pueden observarse en el Cuadro 1.

\section{La política de investigación en la Universidad de Antofagasta (UA)}

Desde su creación, en el año 1981, la UA, como institución clave de aporte cultural en la educación superior de Chile, y en la sociedad del saber, cohesiona retos asociados a las responsabilidades en investigación, en ámbito consolidado y emergente, enmarcados en el Plan de Desarrollo Estratégico Institucional -PDE(2016-2020). Dicho plan indica la promoción de transferencia de conocimientos en ciencia y tecnología mediante la investigación y la innovación en contexto de educación superior. La actividad investigativa, además, considera un compromiso con el desarrollo de la segunda región de Antofagasta a través del fomento de áreas específicas como los procesos minerales, recursos del mar, química básica y energías renovables no convencionales.

Las fortalezas que posicionan a la UA en el escenario para el desarrollo de las ciencias, la investigación y la innovación están determinadas por la Comisión Nacional de Acreditación, $\mathrm{CNA}^{3}$, cuya

3 Para mayor información se sugiere revisar el sitio web https://www.cnachile.cl/res/inst/RESINST-00045-03.pdf 


\section{Cuadro 1}

Indicadores utilizados en los rankings de universidades

\begin{tabular}{|c|c|c|}
\hline $\begin{array}{l}\text { Criterio Indicador } \\
\text { Significado }\end{array}$ & $\begin{array}{l}\text { Criterio Indicador } \\
\text { Significado }\end{array}$ & Criterio Indicador Significado \\
\hline \multirow{2}{*}{$\begin{array}{l}\text { Artículos publicados en } \\
\text { revistas indexadas en el } \\
\text { Journal Citation Reports } \\
\text { (JCR) }\end{array}$} & Producción & $\begin{array}{l}\text { Número de artículos publicados en } \\
\text { revistas de la Colección principal de Web } \\
\text { o Science (WoS) en el año } 2013 \\
\text { indexadas en el JCR. }\end{array}$ \\
\hline & Productividad & $\begin{array}{l}\text { Proporción de artículos publicados en la } \\
\text { Colección principal de WoS en el año } \\
2013 \text { de revistas indexadas en el JCR por } \\
\text { profesores funcionarios. }\end{array}$ \\
\hline \multirow[b]{2}{*}{$\begin{array}{c}\text { Tramos de } \\
\text { Investigación (TI) }\end{array}$} & Producción & $\begin{array}{l}\begin{array}{l}\text { Número total de sexenios } \\
\text { investigación obtenidos por } \\
\text { profesores funcionarios (2009). }\end{array} \\
\text { los }\end{array}$ \\
\hline & Productividad (Índice TI) & $\begin{array}{l}\text { Número de tramos de investigación } \\
\text { obtenidos por los profesores funcionarios } \\
\text { dividido por el número total de tramos de } \\
\text { investigación posibles de esos } \\
\text { funcionarios (2009). }\end{array}$ \\
\hline \multirow{2}{*}{ Proyectos I+D } & Producción & $\begin{array}{l}\text { Número de proyectos I+D concedidos a } \\
\text { cada universidad en la convocatoria de } \\
2013 \text { (tramo en la modalidad de } \\
\text { Excelencia, como de Retos) }\end{array}$ \\
\hline & Productividad & $\begin{array}{l}\text { Proporción de proyectos I+D } \\
\text { (modalidades de Excelencia y Retos) en } \\
\text { la convocatoria de } 2013 \text { por profesores } \\
\text { funcionarios. }\end{array}$ \\
\hline \multirow[b]{2}{*}{ Tesis Doctorales } & Producción & $\begin{array}{l}\text { Número de tesis doctorales defendidas } \\
\text { en un período de cinco cursos (desde el } \\
\text { curso 2007/2008 hasta el curso } \\
2011 / 2012 \text { ). }\end{array}$ \\
\hline & Productividad & $\begin{array}{l}\text { Proporción de tesis doctorales } \\
\text { defendidas, por profesores funcionarios } \\
\text { en un período de cinco cursos (desde el } \\
\text { curso 2007/2008 hasta el curso } \\
2011 / 2012 \text { ). }\end{array}$ \\
\hline \multirow[b]{2}{*}{ Becas FPU } & Producción & $\begin{array}{l}\text { Número de becas FPU concedidas en la } \\
\text { convocatoria de } 2013 \text {. }\end{array}$ \\
\hline & Productividad & $\begin{array}{l}\begin{array}{l}\text { Proporción de } \\
\text { convocatoria de } \\
\text { funcionarios }\end{array} \\
\text { fuls }\end{array}$ \\
\hline \multirow{2}{*}{$\begin{array}{l}\text { Doctorados con } \\
\text { Mención hacia la } \\
\text { Excelencia }\end{array}$} & Producción & $\begin{array}{l}\text { Número de doctorados con Mención } \\
\text { hacia la Excelencia (convocatoria de } \\
\text { 2011) de cada Universidad. }\end{array}$ \\
\hline & Productividad & $\begin{array}{l}\text { Proporción de doctorados con Mención } \\
\text { hacia la Excelencia en la convocatoria de } \\
2011 \text { por profesores funcionarios. }\end{array}$ \\
\hline \multirow{2}{*}{ Patentes } & Producción & $\begin{array}{l}\text { Número de patentes registradas en el } \\
\text { período } 2009-2013 \text { y explotadas en el } \\
\text { período } 2004-2008 \text {. }\end{array}$ \\
\hline & Productividad & $\begin{array}{l}\text { Proporción de patentes registradas de } \\
2009 \text { a } 2013 \text { y explotadas de } 2004 \text { a } \\
2008 \text { por profesores funcionarios }\end{array}$ \\
\hline
\end{tabular}

Nota: los profesores funcionarios incluyen a Catedráticos de Universidad (CU). Catedráticos de Escuela Universitaria (CEU) y Profesores Titulares de Universidad (PTU)

Fuente: Buela-Casal et al (2012), Buela-Casal et al (2015). 
acreditación entregada a la institución es de cuatro años en esta área (agosto 2013-agosto 2017). La fortaleza organizativa del quehacer investigativo, que acredita esta posición temporal, puede entenderse por los cuatro planteamientos vectores definidos en el Plan Estratégico:

Objetivos estratégicos específicos para la investigación: que considera el incentivo para la creación de conocimiento para su integración a la docencia de pregrado y postgrado, la consolidación y fortalecimiento de líneas de investigación científica, el incentivo a la asistencia técnica para los sectores productivos y organismos públicos basado en investigación aplicada y el incentivo para la investigación multidisciplinaria en temáticas relevantes para la región y el país.

Calidad de su talento humano: que incluye excelencia investigativa de la planta docente en virtud de la calidad y productividad de sus investigadores jóvenes e investigadores consolidados asociados a grupos de investigación, centros, institutos y unidades de investigación lo que consta también en el Informe de Acreditación CNA - 2013 al mencionar que "la universidad cuenta con un cuerpo académico equilibrado entre investigadores experimentados y en formación, el que se ha ido renovando" 4 lo que potencia una plataforma sobre la cual levantar actividades investigativas con académicos con experiencia y jóvenes investigadores en razón de un recambio y de una proyección.
Promoción de concursos de investigación: en los últimos tres años (20142015-2016) se están ejecutando programas de apoyo, como CONICYT, Fondo de Innovación para la Competitividad FIC-R y concursos internos de investigación, en tanto valor estratégico para potenciar capacidades de investigación, vinculados al Programa de Fomento de la Investigación en Áreas Escasamente Desarrolladas, Programa de Iniciación en Investigación para Investigadores Jóvenes de la UA, Fondo de Investigación para el Desarrollo de Tesis de Pregrado o Actividad de Titulación y Programa de Semillero de Investigación, los cuales cuentan con una asistencia técnica para su postulación y con foco, preferencial, en jóvenes talentos de reciente incorporación a la universidad.

Consolidación de líneas de investigación científica de la universidad: en la perspectiva de modernizar el quehacer, la UA promueve a los académicos el desarrollo de líneas de trabajo en atención a los requerimientos y problemas tecnológicos del medio en consonancia con los desarrollos estratégicos en capitales naturales renovables de zona desértica, energía, recursos hídricos, sustentabilidad ambiental y salud pública. En este sentido, se levanta una línea emergente, en sus diversas formas de agrupación, llamada Núcleos de Investigación y de la cual se estableció una variante como investigación emergente denominada Núcleos de Investigación en Docencia, coor- 
dinada desde la Vicerrectoría Académica y devenida de un Convenio ministerial: el Convenio de Armonización Curricular -ANT-1308. En este contexto, una fortaleza clave es que existen iniciativas y concursos internos para el desarrollo de la investigación en docencia como una fórmula que materializa un proceso escalado y de trayectorias para el logro de resultados en la gestión de aula y en el efectivo quehacer docente.

El carácter participativo, al integrar a las ocho facultades de la Universidad, sostuvo una decisión institucional esencial, durante los últimos dos años (20142015) al considerar el trabajo de enseñanza aprendizaje en el aula universitaria y el desarrollo escalado, del capital profesional docente en los académicos de jerarquía instructor y asociado, preferentemente, para generar un proceso gradual de capacidades investigativas a nivel individual y en el trabajo colectivo entre pares.

\section{Panorama actual de la investigación en la UA}

El panorama actual de la investigación en la UA adquiere una relevancia institucional en consonancia con los estatutos acerca de la política de investiga- ción, ya que en su artículo 2 se indica que "la Universidad de Antofagasta es una corporación cuya finalidad es el desarrollo y la preservación del saber y la cultura, por medio de la enseñanza, la investigación científica, tecnológica y la creación artística" (D.F.L. N ${ }^{\circ} 148$ del 11 de diciembre de 1981) (Universidad del Antofagasta, 1982).

En este sentido, la unidad articuladora de dicho quehacer incremental es la Vicerrectoría de Investigación, Innovación y Postgrado que, a su vez, materializa el trabajo, en la Dirección de Gestión de la Investigación, potenciando la investigación y sus resultados mediante el incremento de las publicaciones en revistas indexadas y las patentes. En esta línea, la UA presenta una correlación con el aumento en el número de doctores que para el caso de los años 2010-2013 el incremento relativo es de un $29 \%$ vinculado a los índices de productividad de artículos $|\mathrm{SI}|^{5}$.

En el año 2015, la UA impartió tres (3) programas de doctorado, once (11) Programas de Magíster, una (1) especialidad médica. La matrícula en Postgrado ${ }^{6}$ alcanza a 280 estudiantes y en Pregrado $^{7}$ a 7.427 estudiantes. Cabe mencionar que cuenta con una Planta Académica de 560 Académicos, en distintas modalida-

5 La información se encuentra disponible en: http://www.uantof.cl/plan_desarrollo/documentos/interno/05Investigacion.pdf

6 Dato de matrícula al 31 de diciembre del 2015 informado por Escuela de Postgrado de la Universidad de Antofagasta.

7 Dato de matrícula al 30 de abril 2015, desde SIES Matricula de Pregrado (y considera carreras dictadas por las ocho Facultades, Carreras Técnicas, SEC, SED y Planes Especiales). 
des contractuales ${ }^{8}$ de los cuales un $54 \%$ posee el grado de Doctor, Magíster y Especialidades Médicas.

Por otra parte, el énfasis se ha dado por la especialización, los indicadores institucionales de excelencia, la vinculación con el medio y la inclusión de la innovación al quehacer. Estos cuatros aspectos son piedra angular en que se sustentan los indicadores de publicaciones científicas indexadas (Tabla 1) que, a la fecha de 2015, son los siguientes:

Con base en lo anterior, la calidad de la investigación realizada en la UA se potencia con el reconocimiento de un área emergente como es la investigación en docencia universitaria, reconocida por la aplicación de indicadores y criterios que están aceptados en investigación científica de educación tanto en sus dimensiones cuantitativas como cualitativas, lo que aporta insumos para los académicos que trabajan en el fomento y desarrollo de líneas de investigación en docencia.

\section{Justificación de los núcleos}

La actividad académica de los núcleos de investigación, se diseñó pensando primordialmente en buscar fórmulas que permitiesen incrementar el número de publicaciones en las universidades chilenas; especialmente en aquellas que se encuentran ubicadas fuera de la Región Metropolitana, tomando en consideración que uno de los dispositivos que
Tabla 1 Indicadores de publicaciones científicas indexadas

\begin{tabular}{ccccc}
\hline Año & ISI & Scopus & SciELO & Totales \\
\hline 2013 & 120 & 0 & 7 & 127 \\
2014 & 115 & 12 & 6 & 133 \\
2015 & 132 & 15 & 11 & 158 \\
\hline
\end{tabular}

Fuente: Elaboración propia basada en datos de la Universidad de Antofagasta, Dirección de Desarrollo Curricular (2016).

han facilitado el acceso a nuevos saberes son -precisamente- las revistas académicas o científicas, las que se han transformado en una de las herramientas o vehículos más efectivos, sofisticados y rigurosos para dar difusión al conocimiento que se está gestando en todas las áreas disciplinarias (Ganga, Paredes y Pedraja 2015; 112).

En este orden de cosas, y tal como se puede observar en la Tabla 2, en la mayor parte de las entidades ubicadas en regiones, no se superan las 200 publicaciones (ISI, Scielo, Wos) incluso en entidades que tienen sobre 250 académicos. Tanto es así, que durante el año 2015 el promedio de artículos fue 273 (cifra fuertemente influenciada por la Universidades de Concepción, Austral y Valparaíso, que produjeron casi el $40 \%$ del total, sin estas instituciones, la media decrece a 153,7); es decir el índice publiométrico no alcanza a 1; pero el problema mayor está radicado en el hecho de que en la mayoría de estas casas de estudios, aproxima- 
Tabla 2

Publicaciones de universidades chilenas (año 2014-2015)

\begin{tabular}{|c|c|c|c|c|c|c|c|c|c|c|c|c|c|c|c|c|c|}
\hline Universidades Linsorcio d & & $2 \square$ & $\overline{015}$ & & & 20 & $\overline{014}$ & & & & 20 & 15 & & & 2 & 014 & \\
\hline $\begin{array}{l}\text { Rectores de Universidades d } \\
\text { Chile (CRUCH) }\end{array}$ & SeiEL & $\begin{array}{c}\text { SciELD } \\
|S|\end{array}$ & $\begin{array}{c}\text { Wos } \\
(\mathrm{ex}|\mathrm{S}|)\end{array}$ & Total & SciElD & \begin{tabular}{|c|} 
SciELD \\
$|S|$
\end{tabular} & $\begin{array}{c}\text { Wos } \\
(\mathrm{ex}|S|)\end{array}$ & Total & Universidades Privada & SciELD & $\begin{array}{c}\text { SciELD } \\
|S|\end{array} \mid$ & \begin{tabular}{|c|} 
Wos \\
(ex ISI)
\end{tabular} & Total & SciELI & $\begin{array}{c}\text { SciELL } \\
|S|\end{array}$ & $\mid \begin{array}{c}\text { Wos } \\
\text { (ex ISI) }\end{array}$ & Total \\
\hline Católica de Chile & 142 & 152 & 1790 & 2084 & 149 & 276 & 1878 & 2303 & \begin{tabular}{|l|} 
Academia de Humanismo \\
Cristiano
\end{tabular} & 5 & 1 & 7 & 13 & 4 & $\overline{0}$ & 6 & 10 \\
\hline Católica de Valparaíso & 33 & 41 & 430 & 504 & 49 & 68 & 342 & 455 & Addlfo lbáñez & 8 & 8 & 137 & 153 & 14 & $\|$ & 96 & 121 \\
\hline Artura Рrat & 15 & 8 & 52 & 75 & 19 & 14 & 51 & 84 & Adventista de Chile & 0 & 0 & & 1 & 0 & $\overline{0}$ & 1 & 1 \\
\hline Austral de Chile & 20 & 5 & 469 & 540 & 35 & 82 & 392 & 50 呵 & Alberto Hurtado & 21 & 6 & 35 & 62 & 38 & 22 & 57 & 117 \\
\hline \begin{tabular}{|l|} 
Católica de la Santísima \\
Concepción
\end{tabular} & 10 & 12 & 73 & 95 & 4 & 12 & 63 & 79 & Andrés Bello & 17 & 30 & 458 & 505 & 23 & 55 & 418 & 496 \\
\hline Católica de Temuco & 可 & 20 & 107 & 136 & 14 & 25 & 82 & 121 & $\begin{array}{l}\text { de las Artes y ᄃ. de la } \\
\text { Comunicación }\end{array}$ & 0 & - & 0 & 0 & 마 & 0 & & 1 \\
\hline Católica del Maule & g & 8 & 47 & 64 & 10 & 14 & 54 & & $\begin{array}{l}\text { de Arte y Ciencias } \\
\text { Sociales }\end{array}$ & 1 & 0 & & 2 & 1 & 0 & 0 & 1 \\
\hline Católica del Norte & 27 & 31 & 286 & 344 & 32 & 52 & 268 & 352 & Autónoma de Chile & 21 & 38 & 330 & 389 & 24 & 58 & 163 & 245 \\
\hline de Antofagasta & 3 & 13 & 146 & 162 & 4 & 9 & 116 & 129 & Bernardo D'Higgins & 5 & 2 & 38 & 45 & 12 & 3 & 23 & 38 \\
\hline de Atacama & 1 & 1 & 25 & 27 & 5 & ] & 23 & 28 & Balivariana & 0 & 0 & 0 & 0 & - & 0 & 0 & 0 \\
\hline de Chile & 244 & 173 & 2030 & 2447 & 217 & 311 & 1878 & 2406 & Católica Silva Henríquez & 6 & 1 & 5 & 12 & 7 & E & 14 & 27 \\
\hline de Concepción & 65 & 83 & 886 & 1034 & 50 & 117 & 829 & 995 & Central de Chile & 6 & 0 & 28 & 34 & 8 & E & 17 & 31 \\
\hline de La Frantera & 38 & 83 & 390 & 511 & 46 & 1110 & 322 & 478 & de Aconcagua & D & 0 & 0 & 0 & 만 & [ & ] & 만 \\
\hline de La Serena & 6 & 6 & |미 & 113 & 12 & 9 & 96 & 117 & $\begin{array}{l}\text { de Ciencias de la } \\
\text { Informática }\end{array}$ & 0 & 0 & 0 & 0 & 0 & 0 & 0 & 0 \\
\hline de Los Lagos & 14 & 13 & 剅 & 88 & 5 & 14 & 58 & 77 & de Las Américas & 1 & 1 & 2 & 4 & 맘 & 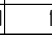 & 1 & 2 \\
\hline de Magallanes & 14 & 4 & 73 & 91 & 4 & I6 & 62 & 82 & de Los Andes & 24 & 29 & 177 & 230 & 30 & 37 & 110 & 177 \\
\hline \begin{tabular}{l|} 
de Playa Ancha de Ciencias de \\
la Educación
\end{tabular} & 14 & 5 & 50 & 69 & 10 & 8 & 34 & 52 & de Viña del Mar & 2 & 2 & 7 & 11 & 2 & 2 & 4 & 8 \\
\hline de Santiago de Chile & 35 & 22 & 437 & 494 & 43 & 49 & 386 & 478 & del Desarrollo & 35 & 24 & 196 & 255 & 50 & 31 & 154 & 235 \\
\hline \begin{tabular}{|l|} 
de Talca \\
\end{tabular} & 34 & 21 & 262 & 317 & 41 & 33 & 249 & 323 & del Mar & D & D & 7 & 7 & 3 & 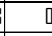 & 2 & 5 \\
\hline de Tarapacá & 40 & 22 & 197 & 259 & 34 & 41 & 197 & 272 & del Pacífico & 만 & 1 & 2 & 3 & 만 & 1 & 3 & 4 \\
\hline \begin{tabular}{|l} 
de Valparaíso \\
\end{tabular} & 37 & 34 & 337 & 408 & 29 & 35 & 293 & 357 & Diego Portales & 38 & 25 & 325 & 388 & 57 & 3 & 241 & 329 \\
\hline del Bío-Bín & 18 & 15 & 156 & 189 & 18 & 13 & 130 & 16 & Finis Теггае & 12 & 5 & 41 & 58 & 5 & 5 & 31 & 41 \\
\hline \begin{tabular}{|l|} 
Metropolitana de Ciencias de la \\
Educación
\end{tabular} & 3 & 5 & 39 & 47 & 5 & 5 & 20 & 30 & Gabriela Mistral & (0) & (0) & 3 & 3 & 5 & 0 & 4 & 可 \\
\hline Técnica Federica Santa María & 2 & 4 & 427 & 433 & 3 & 6 & 336 & 345 & $\begin{array}{l}\text { |b. de Ciencias y } \\
\text { Tecnología }\end{array}$ & 0 & 2 & 4 & 6 & 미 & 1 & 1 & 2 \\
\hline Tecnológica Metropolitana & 만 & 만 & 15 & 15 & & & g & 可 & Internacional SEK & 2 & [0 & 7 & $\mathrm{~g}$ & 1 & 4 & 2 & 7 \\
\hline & & & & & & & & & del Mar & & & 0 & 0 & & & 1 & 1 \\
\hline & & & & & & & & & de La República & 0 & [ & 0 & 0 & 맘 & [ & ? & 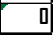 \\
\hline & & & & & & & & & Los Leanes & & & 0 & 0 & & & 0 & 0 \\
\hline & & & & & & & & & Mayor & 8 & 10 & 58 & 76 & 15 & $\|$ & 35 & 61 \\
\hline & & & & & & & & & Miguel de Cervantes & 만 & 만 & ] & 0 & 만 & [ & ] & 0 \\
\hline & & & & & & & & & Pedro de Valdivia & 만 & 1 & 1 & 2 & 만 & [ & 2 & 2 \\
\hline & & & & & & & & & San Sebastián & 15 & 19 & 118 & 152 & 12 & 10 & 39 & 6i \\
\hline & & & & & & & & & Santo Tomás & 16 & 18 & 86 & 120 & 12 & 18 & 50 & 80 \\
\hline & & & & & & & & & Tecnológica de Chile & 1 & 마 & & 2 & 미 & & 3 & 4 \\
\hline
\end{tabular}

Fuente: Elaboración propia, basado en datos de la Comisión Nacional de Investigación Científica y Tecnológica (CONICYT) (2015). 
damente el $70 \%$ de las publicaciones las genera sólo el $30 \%$ de los académicos. De hecho, en la universidad en estudio, del total de publicaciones, sólo el 25,6\% produce el $100 \%$ de estos productos investigativos ${ }^{9}$.

Para enfrentar el desafío que implica incrementar los artículos publicados en revistas indexadas, muchas de las universidades han optado por definir políticas de investigación (con un fuerte componente de incentivos monetarios por publicación generada, creando nuevos centros de investigación -y otras- simplemente contratando académicos a los cuales se les pueda exigir mínimamente dos publicaciones anuales (la mayoría de las universidades están exigiendo a los nuevos doctores una publicación en revistas ISI o Scopus; o en su defecto, dos publicaciones indexadas en SciELO); estas acciones presentan inicialmente al menos tres dificultades:

a. A veces resulta muy complejo transferir el nuevo conocimiento que se genera en los centros de investigación y/o con los investigadores nuevos contratados, al plano de la docencia, especialmente a nivel de carreras de pregrado.

b. Por tratar de acceder a los incentivos, en muchas ocasiones los académicos publican sobre cualquier materia o disciplina, olvidándose de las líneas que la universidad o su unidad académica tiene priorizada; afectando de paso el indicador de especialización. c. Los costos de implementar un centro de investigación y/o contratar una adecuada dotación de académicos que impacte de manera significativa en el indicador, son muy elevados.

Frente a lo anterior, parece razonable, transferir competencias en la generación de artículos científicos al más alto porcentaje posible de docentes que hoy no están publicando en las universidades; argumentos que fueron debidamente ponderados por el equipo directivo de esta casa de estudios superiores decidiendo, por lo tanto, apoyar la respectiva asistencia técnica para su sistematización y desarrollo.

Hoy existe un amplio consenso, en términos de la complejidad de la función docente, pero también en el supuesto que, para mejorar las prácticas pedagógicas de los profesores, estos deben ser capaces de reflexionar e investigar sobre los procesos que desarrollan, con el fin de optimizar los aprendizajes de sus estudiantes, reforzando de esta forma la figura del docente como investigador (Cázares, 2003).

En este sentido, se hace necesario reconocer el conjunto de ideas o esquema teórico subyacente en que se fundamenta este constructo de reflexión y mejora a partir del propio quehacer docente. Es así, como esta actividad denominada Núcleos de Investigación en Docencia se condice con el paradigma sociocrítico de la investigación educativa, donde el gru-

9 Trescientos (300) académicos son de JC (jornada completa) en la Universidad de Antofagasta. De ellos setenta y siete (77) generaron, en el año 2015, la cantidad de ciento cuarenta y dos (142) publicaciones indexadas. 
po asume la responsabilidad de la investigación y propicia la reflexión y crítica de los intereses, interrelaciones y prácticas educativas (Latorre et al, 2005) y, más precisamente, con la investigación acción. Latorre (2004) intentando responder a la pregunta: ¿qué engloba este tipo de investigación en el plano educativo? señala que este responde a una familia de actividades que llevan a cabo los profesionales del ámbito social, en nuestro caso profesionales ligados a la educación superior, con el propósito de mejorar la calidad de sus acciones. No obstante, no sólo en este ámbito se direccionan las investigaciones que procesan y sistematizan los docentes que participan en los Núcleos de Investigación en Docencia de la UA, sino también en aquellos hallazgos que surgen del quehacer docente y que logren ser socializados con el fin de constituirse en un aporte al conocimiento.

Se trata de dar a conocer una experiencia exitosa, como una especie de caso, dado que se tiene como propósito estudiar en detalle, con niveles de profundidad aceptable, una unidad de análisis específica (Bernal, 2006; Martínez, 2006), como es una universidad del Estado de Chile. En este desarrollo, la hipótesis primordial considera un trabajo empírico que consiste en el abordaje de lo específico y particular en el sentido de elegir un objeto para ser estudiado; más específicamente, es de corte descriptivo (Latorre, 2005: 236) que recoge evidencia tanto cuantitativa como cualitativa, la que ha sido orientada a comprender las dinámicas que se han dado en la puesta en práctica de estas vías, tendiente a generar nuevos conocimientos factibles de ser publicados en revistas académicas indexadas.

\section{Los Núcleos de Investigación de la UA (NID-UA)}

En las siguientes sub secciones se muestra información detallada de los núcleos de investigación de la UA:

\subsection{Condiciones de base}

Para lograr colocar en funcionamiento los denominados NID-UA, lo primero que se efectúo fue la realización y materialización de un reflexivo diagnóstico de la situación en la que se encontraba la investigación en la universidad en estudio; al cabo de lo cual se llegó a la conclusión de que era necesario implementar un mecanismo que permitiese involucrar nuevos académicos en la publicación de artículos académicos. La idea anterior, sólo podría tener resultados positivos, si se lograban ciertas condiciones de base:

La primera de ellas, decía relación con alcanzar el involucramiento del equipo directivo superior de la universidad; en este contexto, el trabajo desarrollado desde la Unidad de Gestión Académica (UGA) posibilitó que tanto el rector como el vicerrector académico de la UA se implicarán en este proyecto, entregando desde el comienzo todo el apoyo requerido.

A partir de estas decisiones, se generó la segunda condición, la cual implicó estructurar un plan de mediano plazo y largo plazo, en conjunto con el asesor externo, el que consideró no sólo el apoyo y la transferencia de conocimientos en el ámbito de la publicación de artículos académicos, sino que también la definición de recursos financieros y personas, que 
permitiesen darle un soporte completo a la nueva actividad de los núcleos de investigación.

Una tercera condición era la de funcionar inspirados en la filosofía del trabajo en equipo, por medio del cual, se definieron un conjunto de dispositivos adicionales, los cuales deberían ser coherentes con la idea original de incrementar la cantidad de publicaciones de la unidad en estudio.

La última condición, dice relación con la decisión de difundir y promover ${ }^{10}$ las actividades de los Núcleos de Investigación en Docencia en el ámbito de la divulgación científica, socializando las acciones en la comunidad académica; generando para ello un canal de intercomunicación con las diversas instancias universitarias y audiencias, o públicos objetivos, con el fin de aportar a su posicionamiento como área prioritaria en la institución.

\subsection{Definición}

La actividad académica Núcleos de Investigación en Docencia de la Universidad de Antofagasta (NID-UA) se define como una actividad instalada en una metodología de trabajo colaborativo inter, intra y multidisciplinario, en el contexto de un modelo centrado en el conocimiento y comprensión de un proceso de diagnóstico e intervención que se ha ejecutado a partir de un convenio ministerial. Sus propósitos metodológicos están asociados a una fórmula en que el docente se enfrenta a una problemática concreta con el objetivo de proponer y establecer una "ruta quehacer" (en tanto solución). En dicha estrategia, el docente fomenta sus capacidades en el ámbito de la investigación, el análisis, el estudio de un área, en particular; así como el incremento del área motivacional para el trabajo de investigación en docencia ${ }^{11}$.

El trabajo, planteado en situaciones reales de la docencia universitaria y en problemas disciplinarios, está dirigido a académicos que ejercen la docencia de pregrado, profesionales adscritos a centros, unidades y facultades y de manera eventual, a estudiantes. El propósito de esta iniciativa radica en fortalecer la investigación derivada del quehacer propio de la docencia y capacitar en estrategias para la publicación de artículos científicos. Lo anterior, conlleva, de forma paralela, al aumento de las tasas de publicaciones científicas en revistas indexadas por parte de la institución.

Los NID-UA surgen en el contexto del Convenio de Desempeño ANT 1308, que tiene por finalidad la ejecución y desarrollo del Plan de Mejoramiento Institu-

10 Se destaca el aporte de la Dirección de Vinculación y Comunicaciones de la Universidad de Antofagasta en la divulgación de la actividad a nivel de cobertura, comunicados de prensa, noticias breves, entre otros.

11 Mediante esta técnica el profesor o profesora establece nuevas medidas en su quehacer académico y analiza hechos y acontecimientos relacionados con su desarrollo profesional docente potenciando habilidades en grupo puesto que se establece, también, un trabajo entre pares en tanto proceso de discusión grupal. 
cional (PMI) denominado: "Armonización Curricular para el aseguramiento de la calidad de la oferta educativa de la UA". Esta iniciativa es organizada por la Unidad de Gestión Académica (UGA) ${ }^{12}$, dependiente de la Vicerrectoría Académica (VRA) y es coordinada, institucionalmente, por dos profesionales, quienes además de apoyar las labores de gestión realizan asesoramiento académico a los participantes. En esta misma línea, la actividad cuenta con una asistencia técnica externa $^{13}$, la cual ha sido coparticipe con las autoridades de la universidad, en el diseño, planificación, dirección, coordinación y monitoreamiento de las diversas acciones y dispositivos que se han generado; junto con ello, orienta el quehacer que se realiza con los participantes.

\subsection{Actividades concretas}

En términos del refuerzo que esta actividad contribuye a generar en el ámbito de las competencias docentes, y que por tanto justifica la puesta en marcha de este programa formativo docente al interior de la UA, se pueden mencionar las siguientes acciones:

- Un cambio de enfoque: los docentes de pregrado también investigan y publican. Esto debido a que la investigación educativa no constituía un área prioritaria de atención para los académicos de pregrado.

- Interacción docente: los docentes se comunican entre ellos y comparten sus respectivas experiencias; por ejemplo, jefe de carrera con docentes de media jornada, lo cual fortalece el trabajo colaborativo o en red.

- Desarrollo de estrategias de aprendizaje: los docentes deben realizar lecturas científicas, analizar bases de datos bibliográficas, desarrollar el aprendizaje cooperativo, la investigaciónacción, fomentar la escritura académi$\mathrm{ca}$, etc.

En sintonía con lo anterior, la implementación de los Núcleos de Investigación en Docencia considera múltiples actividades, entre las cuales destaca el desarrollo de talleres dirigidos desde la asistencia técnica externa, que se centran en la metodología para la publicación de artículos científicos en revistas indexadas y en la evaluación de artículos por los pares. Como una manera de potenciar el trabajo que desarrolla el asesor externo, los coordinadores institucionales, previa planificación y acuerdo con dicho asesor, propician otras instancias de formación para los núcleos de investigación constituidos, entendiéndose como tales los docentes agrupados ya sea por pertenencia a algún Departamento, o bien, por el inte-

12 Actualmente esta unidad se encuentra derogada y se denomina Dirección de Desarrollo Curricular del cual depende la actividad Núcleos de Investigación en Docencia; es una dirección de apoyo técnico a la Vicerrectoría Académica de la Universidad de Antofagasta.

13 Esta asistencia técnica externa es realizada por un académico, con un doctorado y un postdoctorado en el ámbito de las ciencias sociales, y que posee un amplio currículo como investigador y en materia de publicaciones científicas. 
rés temático que tienen respecto al área a investigar. Tales instancias abarcan tanto las exposiciones de un determinado tema como las sesiones de seguimiento a cada uno de los grupos de trabajo.

Respecto a las exposiciones temáticas, tienen cabida aquí las siguientes: investigación educativa, escritura académica, la ética en la investigación científi$\mathrm{ca}$, entre otras materias relevantes. Por su parte, las sesiones de seguimiento constituyen una forma de apoyo más directa y contextualizada durante el proceso en que se desarrollan los escritos, ya que permite que los participantes reciban orientación por parte de la coordinación institucional de investigación y especialista en temas educativos (Cuadro 2).

Los Núcleos de Investigación en Docencia comienzan a implementarse al inicio del año académico 2014 y al tratarse de una actividad avalada en un conve- nio ministerial, tiene fecha de caducidad prevista para el mes de diciembre de 2016, esperando que dicha actividad logre consolidarse en el tiempo a través de las políticas institucionales de la Universidad de Antofagasta.

\section{Núcleos de investigación de la UA: Principales resultados sobre su funcionamiento}

Esta parte se centrará en los primeros resultados del funcionamiento de los Núcleos de investigación en Docencia de la UA (Años académicos 2014 y 2015).

\section{- Acciones realizadas por la asisten- cia técnica externa (ATE)}

A partir de año 2014, los núcleos de investigación emergieron como idea gestada en el marco de una asistencia técnica, contratada por la UA. La ATE, en conjunto con las autoridades de la UA encar-

\section{Cuadro 2}

\section{Tareas desarrolladas en las Sesiones de Seguimiento}

Coordinadores de los NID-UA

Comprobar la constitución del núcleo y el área de interés.

Entregar orientaciones, de acuerdo a la temática, para diseñar el artículo.

Sugerir revistas.

Recepcionar el artículo y registrar el título provisorio.

Reenviar el artículo a los pares evaluadores y guiar la revisión de artículos.
Participantes en los NID-UA

Constituir núcleos de acuerdo a interés temático.

Solicitar orientaciones, de acuerdo a la temática, para diseñar el artículo.

Revisar bases de datos y elegir revista para enviar el artículo. Seguir las instrucciones a los autores.

Estructurar el artículo con un título provisorio y enviarlo a los coordinadores.

Participar como "evaluador par" en el taller de revisión de artículos por los pares que dirige el asesor externo.

Fuente: Elaboración propia basada en el Informe: Actividad Núcleos de Investigación en Docencia de la Universidad de Antofagasta (2015). 
gadas del respectivo convenio de desempeño, más el compromiso y apoyo efectivo y real de los máximos directivos de la universidad (rector y vicerrector académico) diseñaron planificaron, organizaron, coordinaron, dirigieron e implementaron las diversas acciones tendientes a colocar en funcionamiento esta iniciativa.

Durante el año 2015, se continuó con los lineamientos del año precedente. El desarrollo de estas jornadas se encuentra en sintonía con los requerimientos específicos de avance de cada grupo de docentes a los cuales se dirige. Por ejemplo, para un grupo se solicitó a la ATE abarcar la temática de los tipos de revistas científicas, mientras que para otro grupo se pidió que abordara el tema de la importancia de los aspectos éticos al momento de desarrollar la investigación científica. Siendo todos ellos temas contenidos en la programación general de la actividad (Tabla 3 ).
Cabe destacar, que el desarrollo de cada una de las visitas del asesor externo se encuentra asociado a un informe, el cual describe detalladamente: el programa de actividades contemplado, los aspectos tratados, el catastro de docentes (con su respectivo listado de asistentes), las notas de prensa originadas en el quehacer, el registro de asistencia escaneado y el archivo de imágenes que da cuenta de la evidencia gráfica del trabajo que se llevó a cabo.

\section{- Reuniones del equipo coordinador institucional: \\ Con la finalidad de organizar cada} una de las acciones que conlleva el desarrollo de la actividad, de forma periódica los coordinadores institucionales (y en ocasiones, con la participación del asesor externo) se reúnen para establecer los pasos a seguir en cada una de las actividades, la forma de atender los requerimientos y organizar el seguimiento que

\section{Tabla 3}

Visitas asesor externo y catastro de asistencia por año

\begin{tabular}{cccccc}
\hline Año & $\mathrm{N}^{\circ}$ & Fecha & Convocados & Asistencia & Convocatoria \% \\
\hline 2014 & 1 & 28 de febrero & 17 & 17 & $100 \%$ \\
& 2 & 28,29 y 30 de abril & 43 & 28 & $65 \%$ \\
& 3 & 19 de junio & 11 & 9 & $82 \%$ \\
& 4 & 17 de octubre & 24 & 14 & $58 \%$ \\
\hline \multirow{2}{*}{2015} & 1 & 29 de abril & 26 & 22 & $85 \%$ \\
& 2 & 09 y 10 de junio & 52 & 39 & $73 \%$ \\
& 3 & 25 y 26 de agosto & 63 & 44 & $70 \%$ \\
& 4 & 28 de octubre & 41 & 30 & $73 \%$ \\
& 5 & 25 de noviembre & 88 & 37 & $42 \%$ \\
& 6 & 13 de enero & 61 & 37 & $61 \%$ \\
\hline
\end{tabular}

Fuente: Elaboración propia basada en el Informe: Reporte de actividad académica Núcleos de Investigación en Docencia (2015 y 2016). 
se le debe hacer a los académicos participantes. Así mismo, a diario deben interactuar para hacer el traspaso de informaciones vía correo electrónico. En este contexto, se desarrollan sesiones de trabajo presenciales, pero también mediante el uso de telefonía (por encontrarse en campus diferentes y la presencialidad resulta a veces compleja). La Tabla 4 muestra los datos referidos a este aspecto.

\section{- Sesiones de seguimiento}

A partir del apoyo y la asesoría que realiza el relator externo, sobre la metodología para la publicación de artículos científicos en revistas indexadas, se motiva y se direccionaliza a los académicos que participan a que elaboren, de manera conjunta sus propios textos académicos; constituyendo, de manera paralela, los núcleos de investigación.

Para lograr este propósito y entendiendo que el trabajo que deben realizar los docentes debe ser guiado, los coordinadores institucionales de la actividad desarrollan sesiones de seguimiento a los grupos, con el fin de acompañarles para atender las posibles dudas y requerimientos que vayan surgiendo. Una de las características de estas sesiones es que pueden ser solicitadas a lo largo de todo el transcurso de la actividad. En este sentido, el representante de núcleo es quien debe solicitarlas y de ser necesario, los coordinadores las planifican.

Estas sesiones de encuentro, entre académicos y coordinadores institucionales, permiten desarrollar un trabajo basado en el diálogo y el estudio de los aspectos que inciden en la gestión pedagógica y por extensión, en el aprendizaje de los estudiantes, estableciendo en ese

\section{Tabla 4}

Reuniones del equipo coordinador

\begin{tabular}{lc}
\hline \multicolumn{1}{c}{ Tipo de reunión } & $\begin{array}{c}\mathrm{N}^{\circ} \text { de } \\
\text { reuniones }\end{array}$ \\
\hline Reuniones presenciales & 16 \\
Reuniones presenciales con & 6 \\
asesor externo & \\
TOTAL & 22 \\
\hline
\end{tabular}

Fuente: Elaboración propia basada a partir del Informe: Reporte de actividad académica Núcleos de Investigación en Docencia (2015).

proceso, que dichos aspectos son susceptibles de proyectar en acciones de investigación (ya realizadas o pronto a ponerse en práctica) que puedan ser formuladas a través de artículos científicos publicables en revistas indexadas.

De igual modo, las sesiones de seguimiento propician apoyo y una retroalimentación específica, toda vez que desde la coordinación de investigación se entregan las orientaciones en razón de las líneas de trabajo, material teórico, ejemplos de investigaciones similares a la temática, entre otros, de acuerdo a las necesidades contextuales de cada uno de los equipos de trabajo constituidos. En ese sentido, por ejemplo, si el grupo plantea una investigación sobre el desarrollo de una nueva forma de enseñar, se le facilitarán textos referidos a la innovación metodológica, pautas a desarrollar según la estructura de organización de la descripción de la experiencia y sugerencias de revistas indexadas que recogen este tipo de temáticas. Cabe destacar, que durante el año académico 2015 se registraron dieciséis sesiones de seguimiento efectuadas. 


\section{- Ceremonia institucional}

La versión 2014 de la actividad finalizó con una ceremonia institucional en donde se otorgaron las certificaciones a los docentes que habían participado. Además, se entregó una edición compendiada con el resumen de cada uno de los trabajos realizados. Esa misma edición, a petición del Vicerrector Académico, fue derivada vía correo postal a los miembros de la Junta Directiva de la institución y a los decanos de las distintas facultades. Se destaca que en esta ceremonia, hubo dos conferencias: en primera instancia, se invitó a una académica de destacada trayectoria investigativa tanto a nivel nacional como internacional, quien expuso acerca de la "temática de la investigación en ciencias sociales: una aproximación a las publicaciones desde un proyecto de investigación en Educación". A su vez, el relator externo, centró su presentación en los "desafíos de gobierno universitario en la promoción de la investigación de las universidades ubicadas fuera de la región metropolitana". Todas estas actividades dieron un marco de importancia y trascendencia del respectivo proyecto, lo cual generó una motivación intrínseca en cada uno de los participantes y grupos de interés.

\section{- Inclusión de actividades en agenda institucional}

La calendarización de las visitas del asesor externo 2015, fueron debidamente formalizadas y reconocidas en las actividades centrales de la universidad, tanto es así que éstas fueron incluidas en la programación académica oficial de la UA. (Calendario de Actividades Académicas y Estudiantiles 2015-2016, sancionado en el Consejo Académico de la Institución). Lo anterior, refleja la importancia que esta actividad ha logrado en la universidad y la posición estratégica que la entidad le otorga como hito relevante de la investigación institucional.

\section{- Oficialización de la actividad}

Esta idea nace a partir de las sugerencias derivadas por la Comisión de Seguimiento del Ministerio de Educación en el mes de junio de 2015, a raíz de las gestiones que realizaron los coordinadores institucionales de la actividad. Dichas gestiones incluyen entre otras, los siguientes procedimientos: reuniones con el vicerrector académico para solicitar orientaciones generales; consultas específicas al Director Jurídico respecto al quehacer docente de quienes participan en los núcleos de investigación; recopilación, desde el departamento de Recursos Humanos, de los antecedentes y la descripción de la actividad académica de los docentes inscritos; contacto con el presidente del comité de ética en investigación científica de la institución, para que redacte un escrito referido a la ética en la investigación científica y sea incorporado al documento de la oficializado ${ }^{14}$.

\section{- Horario protegido}

Durante el año 2015 se establece el horario protegido para los docentes 
que participan en los Núcleos de investigación. Esta formalidad queda señalada en el Decreto que oficializa dicha actividad. La idea de esta franja horaria, de tres horas cronológicas, es para que los académicos involucrados en los respectivos núcleos, tengan un tiempo especial, debidamente reconocido para dedicarse, de manera exclusiva, en sus respectivos artículos académicos.

\section{- Talleres teóricos-prácticos}

A partir de los requerimientos y necesidades formativas detectadas en la relación de trabajo permanente y sistemático con el mundo académico, se programaron una serie de talleres que combinaban adecuadamente aspectos complementarios, tanto desde una óptica teórica como empírica; para mayor información, en Cuadro 3, se lista el nombre de los talleres, con sus respectivos objetivos más relevantes.

\section{- Solicitud de apoyo al Comité de Éti- ca en Investigación Científica de la institución}

En el segundo semestre del año académico 2015, tuvo lugar una reunión estratégica, orientada a la socialización y solicitud de apoyo del Comité de Ética en Investigación Científica de la UA. En esta instancia participó el respectivo Presidente del Comité junto a algunos de sus miembros. El propósito de este encuentro -presidido por uno de los integrantes de la coordinación institucional de los núcleos- fue dar a conocer las características de la actividad académica Núcleos de Investigación en Docencia y a la vez, solicitar una red de apoyo que permitiera velar por el cumplimiento de las normas éticas en las investigaciones que realizan los docentes que participan en los núcleos de investigación.

Los aspectos acordados fueron: el Comité de Ética en Investigación Científica realizará jornadas para dar a conocer la importancia del tema ético en la investigación científica y las características del trabajo que realizan como organismo acreditado; dicha jornada estará dirigida a todos los participantes de la actividad Núcleos de Investigación en Docencia; los integrantes de dicho comité sugieren que las jornadas se realicen haciendo uso del horario protegido $\mathrm{UA}$, se promocione la actividad vía página web, correos electrónicos, oficios VRA, etc. con un razonable tiempo de antelación para que gran parte de los docentes puedan asistir y la coordinación institucional de los núcleos se compromete a gestionar los aspectos relacionados con la implementación: uso de auditorio, generación de documentos oficios, promoción en la Web, entre otros.

\section{- Socialización del estado de la acti- vidad con secretarios docentes y de investigación}

En el último trimestre del año 2015 tuvo lugar una reunión de socialización y sensibilización, respecto al actual estado en que se encontraba la actividad académica. Dicho encuentro estuvo presidido por los coordinadores institucionales de los Núcleos de Investigación en Docencia, el vicerrector académico y el vicerrector de investigación, innovación y postgrado. Al encuentro concurrieron seis representantes de las ocho facultades de la universidad.

\section{- Entrega de certificación}

A partir del año académico 2015 se decide que la entrega de la certificación 


\section{Cuadro 3 \\ Nombre de los talleres y objetivos fundamentales}

Nombre del taller

Introducción al Taller Núcleos

de Investigación en Docencia.

Fundamentos básicos de la escritura académica. Parte I

Fundamentos básicos de la escritura académica. Parte II

Propósitos más importantes

- Presentar las características de la actividad.

- Recoger información actualizada de los docentes que integrarán los Núcleos de Investigación.

- Comprender sentidos generales de la lectura/escritura.

- Determinar líneas asociadas a la escritura académica.

- Explicar sentido tipológico de un académico escritor.

- Desarrollar nociones asociadas a las propiedades generales de un texto académico.

Investigación en la práctica docente • Entender la investigación como una herramienta de formauniversitaria. ción docente.

La Investigación Educativa.

- Entregar herramientas para desarrollar investigación educativa.

Metodología para la publicación de artículos científicos en revistas indexadas.

- Establecer la importancia de la investigación y de la escritura académica.

- Conocer la conceptualización, finalidad, estructura y contenidos del artículo científico.

Constitución de Núcleos de Investigación.

- Formar Núcleos de Investigación según temática de interés.

- Elegir un representante por cada Núcleo de Investigación generado.

- Establecer un horario semanal de trabajo.

- Iniciar el desarrollo de la investigación/artículo científico.

Tipos de revistas científicas. - Conocer las diversas revistas científicas disponibles para publicar los trabajos de investigación.

- Revisar las bases de datos y elegir las revistas más apropiadas según factibilidad de envío de artículos.

- Conocer las normas de publicación.

La evaluación de artículos científicos.

Análisis de los artículos por los pares.

- Identificar los criterios considerados en la evaluación de artículos científicos..

- Analizar los artículos generados considerando los criterios establecidos en la evaluación de artículos científicos.

- Generar feedback a partir de la revisión cruzada de artículos.

Reflexión en torno al tema ético - Sensibilizar respecto al tema ético en la investigación. en la investigación.

- Dar a conocer los lineamientos en torno al tema ético institucional involucrado en el desarrollo de la investigación.

Taller de Inducción a los Proyectos - Dar a conocer qué son y qué caracteriza a los Proyectos de de Docencia UA Docencia de la Universidad de Antofagasta.

Fuente: Elaboración propia basada en el Informe: Reporte de actividad académica Núcleos de Investigación en Docencia (2015). 
será más restringida. Esto, porque en la ceremonia institucional de la versión 2014, si bien se destacó certificando a aquellos docentes que culminaron publicando su artículo, también se entregó diploma a quienes participaron pasivamente de la actividad, es decir, a aquellos docentes que no llegaron a publicar y que, pese a su alto nivel de avance, no presentaban interés en enviar sus trabajos a revistas indexadas. Por tanto, a partir de 2015, se consensuó en que se certificaría a los académicos que generaran un producto evidenciado en revista indexada.

\section{- Coberturas de gestión}

La primera versión, que comprende el año académico 2014, estuvo dirigida a tres Facultades: Medicina y Odontología, Ciencias de la Salud y Educación; dos Centros: Nivelación Académica (CENA-UA) e Innovación y Desarrollo Curricular (CIDEC-UA) y dos unidades: Unidad de Gestión Académica (UGA) y la Unidad de Informática (UI), abarcando a un total de treinta y un participantes. EI desglose de la cantidad de participantes se puede apreciar en la Tabla 5.

Cabe destacar, que de los participantes que hubo durante el programa piloto del año 2014, varios de ellos se consolidaron como investigadores y continuaron con sus escritos, tributando así a los resultados obtenidos hacia la actividad Núcleos de investigación en Docencia. Por su parte, en su segunda versión, que comprende el año académico 2015, esta iniciativa estuvo dirigida a las cinco facultades que no habían sido consideradas en la prueba piloto: Ingeniería; Ciencias Sociales, Artes y Humanidades; Ciencias del Mar y Recursos Biológicos;

\section{Tabla 5}

\section{Cobertura de gestión año 2014}

Facultad / Unidad / Centro $N^{\circ}$ de Docentes

\begin{tabular}{lc} 
Facultad de Educación & 7 \\
Facultad de Medicina y & 7 \\
Odontología & \\
Facultad de Ciencias de la & 7 \\
Salud & \\
Centro de Innovación y & 2 \\
Desarrollo Curricular & \\
Centro de Nivelación & \\
Académica & \\
Unidad de Gestión & \\
Académica & \\
Unidad de Informática & \\
TOTAL & 31 \\
\hline
\end{tabular}

Fuente: Elaboración propia basada en el Informe: Reporte de actividad académica Núcleos de Investigación en Docencia (2015).

Ciencias Básicas y Ciencias Jurídicas. Sin perjuicio de esto, también tuvieron cabida quienes siendo de las facultades atendidas el 2014 no habían participado (Tabla 6).

En el desarrollo e implementación de la actividad, resulta importante destacar que el criterio de selección de los participantes fue atender a las sugerencias que las decanaturas indicaban respecto de los nombres de los académicos interesados por formar parte de esta iniciativa académica. La cantidad de participantes que se integraron a la actividad, en el último trimestre del año 2014, incidió que se ampliara el equipo de coordinación integrando a dos profesionales, desde el Centro de Innovación y Desarrollo Curricular (CIDEC-UA) para apoyar las labores de gestión y de asesoramiento académico. 


\section{Tabla 6}

\section{Cobertura de gestión año 2015}

\section{Facultad / Unidad / Centro}

Facultad de Ciencias Básicas

Facultad de Ciencias Jurídicas

Facultad de Ingeniería

Facultad de Ciencias Sociales, Artes y Humanidades

- Grupo Diseño Gráfico

Facultad de Ciencias del Mar y Recursos Biológicos $\mathrm{N}^{\circ}$ de Docentes

Facultad de Ciencias de la Salud

- Grupo Tecnología Médica

- Departamento de Enfermería 16

- Departamento de Obstetricia

- Grupo Ciencias de la Rehabilitación y del movimiento humano

Profesionales del ámbito de la gestión

Grupo de docentes que participan desde el año 2014

- Medicina y Odontología

- Educación

TOTAL

Fuente: Elaboración propia basada a partir del Informe: Reporte de actividad académica Núcleos de Investigación en Docencia (2016).

De manera extensiva, otras implicancias directas en el tenor de la actividad son el grado de participación académica de nuevos integrantes y el trabajo de algunos docentes, que se mantienen desde el año anterior (como los profesores de la Facultad de Medicina y Odontología y de la Facultad de Educación) los cuales desarrollan un trabajo autónomo y sólo reportan sus resultados a los coordinadores. El resto de los académicos se reúne de manera periódica y se mantiene al tanto de las acciones realizadas.

\section{- Valoración de la actividad}

Al término del año académico 2015 se aplicó una encuesta de satisfacción a los participantes con el objeto de conocer la percepción sobre el funcionamiento de la actividad académica Núcleos de Investigación en Docencia (organización general, contenidos abordados, relatoría externa, sesiones de seguimiento). Los resultados preliminares dan cuenta de cinco situaciones claves, dignas de resaltar (dos de alta valoración y tres que implican desafíos):

- Alta apreciación de la actividad, en todas sus dimensiones,

- Óptimo acompañamiento a los académicos,

- Mejorar las asignaciones de trabajo personal y grupal, 
- Optimizar los horarios de reunión,

- Considerar nuevos inputs como plan de mejora de la iniciativa.

\section{- Resultados complementarios}

a. Incorporación de dos Departamentos. Los académicos del Departamento de Enfermería (16 docentes) y de Obstetricia (11 docentes), a través de la gestión de los directores de dichas unidades académicas, han creado su propio Núcleo de Investigación, con el apoyo del equipo coordinador central. Para el año académico 2015, solicitaron la asistencia técnica especializada permanente, tanto de los coordinadores institucionales, como del asesor externo; lo cual fue aceptado y trabajaron con un alto nivel de entusiasmo en sus metas investigativas y publiométricas.

b. Anexión de dos grupos de académicos afines a una carrera. Se integran como equipo de trabajo un grupo de docentes de Diseño Gráfico (8 docentes) y otro de Cs. de la Rehabilitación y del Movimiento Humano (4 do- centes nuevos más dos que ya habían iniciado su actividad anteriormente). La incorporación de los diversos grupos de académicos incide para que la programación de las actividades de los grupos sea diferente, ya que existe una gradualidad en la entrega de contenidos previstos en dicha programación. Por extensión, el trabajo realizado se caracteriza por ser contextualizado a las particularidades de cada núcleo participante.

\section{- Artículos científicos generados}

Los artículos que se gestaron durante los años 2014 y 2015, presentan diversos niveles de avance: publicado, enviado a revista, aceptado en revista, con alto nivel de avance, con nivel de avance medio, ponencia presentada en congreso, seminario, etc. (Tablas 7 y 8 ).

Cabe destacar, que durante el periodo 2014, los artículos generados atendieron a temáticas docentes y temáticas disciplinarias, según las áreas de procedencia de los diversos académicos. En ese sentido, se decidió aceptar a quienes

Tabla 7

Artículos generados, periodo 2014

\begin{tabular}{|c|c|c|c|c|c|c|}
\hline \multirow{2}{*}{$\begin{array}{c}\text { ESTADO DE LOS } \\
\text { ARTícuLOS GENERADOS }\end{array}$} & \multicolumn{5}{|c|}{ Tipo de publicación } & Total \\
\hline & ISI & scopus & SCIELO & $\begin{array}{l}\text { LATINDEX } \\
\text { CATÁLOGO }\end{array}$ & $\begin{array}{c}\text { COMITÉ } \\
\text { EDITORIAL }\end{array}$ & \multirow{5}{*}{$\begin{array}{c}29 \\
\text { ARTÍCULOS } \\
\text { GENERADOS }\end{array}$} \\
\hline PUBLICADOS & 1 & 3 & 1 & 2 & 2 & \\
\hline $\begin{array}{l}\text { ENVIADO A REVISTA, EN } \\
\text { PROCESO DE } \\
\text { EVALUACIÓN }\end{array}$ & 1 & - & 3 & - & - & \\
\hline $\begin{array}{l}\text { PONENCIA PRESENTADA } \\
\text { EN CONGRESO }\end{array}$ & \multicolumn{3}{|c|}{$\begin{array}{l}\text { CON ALTO NIVEL DE } \\
\text { AVANCE }\end{array}$} & \multicolumn{2}{|c|}{$\begin{array}{c}\text { SE DESCONOCE EL NIVEL DE } \\
\text { AVANCE }\end{array}$} & \\
\hline 3 & \multicolumn{3}{|c|}{13} & \multicolumn{2}{|c|}{1} & \\
\hline
\end{tabular}

Fuente: Elaboración propia basada en el Informe: Reporte de actividad académica Núcleos de Investigación en Docencia (2015). 
Tabla 8

Artículos generados, periodo 2015

\begin{tabular}{|c|c|c|c|c|c|c|c|c|}
\hline \multirow[b]{2}{*}{$\begin{array}{l}\text { ESTADO DE } \\
\text { LOS } \\
\text { ARTÍCULOS } \\
\text { GENERADOS }\end{array}$} & \multicolumn{7}{|c|}{ Tipo de publicación } & Total \\
\hline & ISI & SCOPUS & SCIELO & $\begin{array}{l}\text { LATINDEX } \\
\text { CATÁLOGO }\end{array}$ & $\begin{array}{l}\text { LATINDEX } \\
\text { DIRECTORIO }\end{array}$ & $\begin{array}{l}\text { CAPÍTULO DE } \\
\text { LIBRO CON } \\
\text { COMITÉ } \\
\text { EDITORIAL }\end{array}$ & $\begin{array}{c}\text { LIBRO } \\
\text { COMITÉ } \\
\text { EDITORIAL }\end{array}$ & \multirow{5}{*}{$\begin{array}{c}38 \\
\text { ARTículos } \\
\text { GENERADOS }\end{array}$} \\
\hline PUBLICADOS & - & 3 & 1 & 1 & 1 & 5 & 1 & \\
\hline \begin{tabular}{|l|} 
ACEPTADO EN \\
REVISTA
\end{tabular} & - & - & 1 & - & - & - & - & \\
\hline \begin{tabular}{|l|} 
PONENCIA \\
PRESENTADAS \\
EN CONGRESO
\end{tabular} & \multicolumn{3}{|c|}{$\begin{array}{l}\text { ARTÍ́CULO CON NIVEL } \\
\text { DE AVANCE INICIAL }\end{array}$} & \multicolumn{2}{|c|}{$\begin{array}{l}\text { ARTí́CULO CON NIVEL DE } \\
\text { AVANCE MEDIO }\end{array}$} & & $\begin{array}{c}\text { SE } \\
\text { DESCONOCE } \\
\text { EL NIVEL DE } \\
\text { AVANCE }\end{array}$ & \\
\hline 11 & & 3 & & & 5 & & 2 & \\
\hline
\end{tabular}

Fuente: Elaboración propia basada en el Informe: Reporte de actividad académica Núcleos de Investigación en Docencia (2016).

realizaban trabajos en otras áreas, ya que como instancia de apoyo los núcleos de investigación en docencia aún no especificaban formalmente su énfasis en la gestión docente.

Por otra parte, para el año 2015 (tabla 8), destaca la participación de académicos en distintos seminarios y congresos de investigación presentando ponencias o póster que dan cuenta de sus trabajos en la iniciativa Núcleos de Investigación.

Cabe destacar, que de los treinta y ocho artículos generados en el periodo 2015 , treinta y dos corresponden a escritos que desarrollan la investigación en temas docentes y sólo tres (dos de ellos publicados) obedecen a áreas disciplinarias específicas.

\section{- Plan de mejora}

Con el objeto de asegurar la calidad de este programa formativo en investigación se sugiere una serie de acciones:

a. Acciones previstas a corto plazo:

- Implementación de página Web que almacene los datos de la actividad en tanto información general y como repositorio.

- Adaptar las temáticas que desarrolla el asesor externo a las necesidades contextuales específicas de los docentes participantes, primordialmente por la diversidad de áreas disciplinarias que existen en la universidad.

- Contratación de un profesional que apoye las labores de gestión y asesoría académica.

- Disponer de un espacio físico, o sala de reuniones de carácter permanente, para la atención adecuada de los participantes.

b. Acciones a mediano y largo plazo:

- Resguardar el uso del horario protegido: pese a que se cuenta con un horario protegido debidamente decretado, los docentes mantienen problemas de asignación de horas al trabajo desarrollado en el contexto de los núcleos de investigación en docencia. Realizar el anclaje y el respeto del horario permanente, evitará la deserción y/o la desmotivación de los aca- 
démicos, en este relevante quehacer institucional.

- Establecer una especie de convenio independiente: cada académico integrante de la iniciativa puede asumir un convenio de trabajo en núcleos (tipo convenio de desempeño personal), con el objetivo de establecer y resguardar los deberes y derechos relacionados con esta actividad.

- Normar institucionalmente la participación de la actividad: en este sentido se pueden resguardar los mecanismos necesarios que avalen el seguimiento de la participación de los docentes, verbi gratia: exigiendo excusas formales, si no se asiste a una sesión o actividad de trabajo debidamente planificada.

- Asegurar que los artículos se concluyan y se presenten en revistas: se tiene que contar con acciones de seguimiento efectivas, de tal manera que los académicos logren concluir, sus correspondientes documentos.

- Mirar con óptica de largo plazo los núcleos investigativos: se debe incorporar el tema de las nuevas vías de fomento de las publicaciones científicas, en cada reflexión de carácter estratégico que se realice en la institución.

- Coordinar de manera efectiva a las vicerrectorías involucradas: las formas de implementar estas acciones de corto, mediano y largo plazo se contextualizan por la vía de la dependencia académica de la actividad, es decir, la Vicerrectoría Académica, la cual debe estar debidamente coordinada con la dependencia funcional y/o técnica, como lo es la Vicerrecto- ría Investigación, Innovación y Postgrado de la universidad.

\section{Reflexiones finales}

La Formación de Núcleos de Investigación en Docencia en la Universidad de Antofagasta es una acción con resultados notables tanto en el modo de operar y convocar a los docentes de pregrado a participar de una iniciativa de investigación, como por el hecho de generar compromisos con la calidad y los procesos de formación académica. Esta actividad es organizada por la Unidad de Gestión Académica (UGA), dependiente de la Vicerrectoría Académica (VRA) y es coordinada, institucionalmente, por dos profesionales, uno de los cuales tiene un Doctorado en educación y el otro, es Magister en educación con una certificación en I+D+I. El objetivo de esta iniciativa es capacitar a los académicos para publicar artículos científicos en revistas especializadas por ello, el foco de trabajo está puesto en los retos que demanda publicar un artículo científico, las recomendaciones necesarias para llevar a cabo dicha tarea y las convenciones de escritura que conlleva desarrollar este tipo de difusión del conocimiento. La implementación de este programa de formación considera una asistencia técnica externa, la cual es realizada por un profesional que posee un amplio currículo en materia de publicaciones científicas.

Así pues, se concluye que los Núcleos de Investigación en Docencia han potenciado una serie de acciones:

- La oficialización de su quehacer académico como actividad institucional. 
- La inclusión de la asistencia técnica externa, en la calendarización académica oficial de la institución.

- La priorización de líneas de investigación que fortalecen la docencia.

- La participación de varios académicos en seminarios y congresos con ponencias de investigación.

- La aceptación de artículos en revistas indexadas.

- La organización de cada núcleo, constituido de acuerdo a un patrón establecido previamente.

En este mismo contexto y a dos años del desarrollo de la actividad, se destaca lo siguiente: se mantiene la asistencia técnica externa, se potencian las sesiones de seguimiento, se refuerza la realización de los talleres de escritura académica y se continúan formalizando las acciones. Estas decisiones son fundamentales y trascendentes, dado que las apuestas en este ámbito no pueden ser cortoplacistas; muy por el contrario, requieren de una disposición de carácter estratégico y por lo tanto le corresponden tener un horizonte de largo plazo, pues se debe trabajar por cimentar una cultura orientada a transformar el conocimiento que se genera, en publicaciones en revistas indexadas y esto, evidentemente no se pude lograr instantáneamente.

Por otro lado, los logros relevantes son el alto nivel de participación por parte de los docentes y que la actividad Núcleos de Investigación se institucionaliza, dándoles la formalidad que estas acciones demandan.

En cuanto a logros no previstos, se encuentran las publicaciones que esca- pan al ámbito de la docencia, las que, sin embargo, acrecientan el potencial investigativo de la universidad a nivel de indicador global.

Es importante destacar también, que la actividad académica NID-UA surge como respuesta a la necesidad de innovar en el aula y por el hecho de que los docentes necesitan introducir una forma participativa de aprendizaje e investigación al interior de la docencia de pregrado; resultados que requieren de una adecuada difusión. Representan grupos de interés conformados por docentes afines, según disciplina, pero que conectados con otros pares pueden trabajar temas de gestión pedagógica o de administración de aula o ámbito disciplinarios con la supervisión de un mentor o "coaching paper".

Se espera que la sistematización de esta experiencia, sirva de inspiración a otras entidades educativas que tienen en su planeamiento y pensamiento estratégico la idea de contribuir a la sociedad y a la difusión del conocimiento, incrementando el número de publicaciones que emergen desde la acción investigativa de sus respectivos docentes.

\section{Referencias bibliográficas}

Ander-Egg, Ezequiel (2008), Métodos y técnicas de investigación social I: acerca del conocimiento y del pensar científico, Argentina: Editorial Distribuidora Lumen SRL, 2001.

Buela-Casal, Gualberto; Bermúdez, M. Paz; Sierra, Juan; Quevedo-Blasco, Raúl; Castro, Ángel y Guillén-Riquelme, Alejandro (2012), Ranking 2011 en producción y productividad en investigación de las universidades públicas 
españolas, Revista Psicothema Vol. 24, No 4. pp. 505-515.

Buela-Casal, Gualberto; Quevedo-Blasco, Raúl y Guillén-Riquelme, Alejandro (2015), Ranking 2013 de investigación de las universidades públicas españolas, Revista Psicothema, Vol. 27, No 4. pp. 317-326.

Bunge, Mario (2007), La investigación científica. Su estrategia y su filosofía, España: Editorial Siglo XXI Editores S.A. de C.V.

Castells, Manuel (2012), La institución universitaria en la era de la información. En: La educación en la sociedad de la información y del conocimiento, II Foro Internacional Valparaíso. España: Editorial Ariel, S.A.

Cázares, Delia (2003), El profesor como investigador: una perspectiva crítica, Investigación Educativa Duranguense, 1(2), 4-10.

Díaz Barriga, Ángel (2005), El profesor de educación superior frente a las demandas de los nuevos debates educativos, Perfiles Educativos, tercera época, vol. XXVII, núm. 108, pp. 9-30.

Ganga, Francisco, Lorena Paredez y Pedraja, Liliana (2015), Importancia de las publicaciones académicas: algunos problemas y recomendaciones a tener en cuenta, Revista Idesia, vol. 33, núm. 4, pp. 111-119.

Imbernon, Francisco (2012), La investigación sobre y con el profesorado. La repercusión en la formación del profesorado ¿cómo se investiga? REDIE. Revista Electrónica de Investigación Educativa, Visitado el 27 de marzo de 2016. http://www.redalyc.org/pdf/155/ 15525013001.pdf

Equipo de Coordinación Núcleos de Investigación (2016), Reporte de actividad académica Núcleos de Investigación en Docencia.
Equipo de Coordinación Núcleos de Investigación (2015), Reporte de actividad académica Núcleos de Investigación en Docencia.

Equipo de Coordinación Núcleos de Investigación (2015), Informe Interno actividad Núcleos de Investigación en Docencia de la Universidad de Antofagasta.

Gómez de Silva, Guido (2013), Breve diccionario etimológico de la lengua española, México: Editorial Fondo de Cultura Económica.

Latorre Beltrán, Antonio., Del Rincón Igea, Delio, y Arnal, Justo (2005), Bases metodológicas de la investigación educativa, Barcelona: Ediciones Experiencia.

Latorre, Antonio (2004), La investigación-acción: conocer y cambiar la práctica educativa, Barcelona: Graó.

Martínez, Juan Bautista (coords.) (2012), Innovación en la universidad. Prácticas, políticas y retóricas, Madrid: Graó.

OCDE, CEPAL, CAF (2015), Perspectivas económicas de América Latina 2015, Educación, competencias e innovación para el desarrollo, Visitado el 29 de marzo de 216: http://repositorio.cepal.org/bitstream/handle/11362/37445/S1420759_es.pdf

Ordorika, Imanol y Rodríguez, Roberto (2010), Los rankings en el Mercado del prestigio universitario, Revista Perfiles Educativos, Vol. XXXII, No 129. pp. 8-29.

Stake, Robert (1994), Investigación con estudio de caso, Madrid: Morata.

Universidad de Antofagasta (1982), Estatuto de la Universidad de Antofagasta, Visitado 21 de abril de 2016: http://www.uantof.cl/transparencia/doctos/D.F.L_148_1982.PDF

Universidad de Antofagasta (2013), Convenio de Desempeño: “Armonización curricular para el aseguramiento de la 
calidad de la oferta educativa de la Universidad de Antofagasta".

Universidad de Antofagasta (2013), Oficializa Política de Investigación y plan de acción de la política de investigación de la Universidad de Antofagasta, Decreto $\mathrm{N}^{\circ} 367$.

Universidad de Antofagasta (2013), Armonización Curricular para el aseguramiento de la calidad de la oferta educativa de la Universidad de Antofagasta, Visitado 22 de abril de 2016: http://www.mecesup.cl/usuarios /MECESUP/File/2014/FDI/IA/ANT1308PMI.pdf
Universidad de Antofagasta (2014), Cuenta de gestión 2014. Archivo interno PDF.

Universidad de Antofagasta (2015), Resumen currículum, Documento interno DGI.

Universidad de Antofagasta. (2016), Concursos internos Vicerrectoría de Investigación, Innovación y Postgrado, Visitado 21 de abril de 2016: https://www.uantof.cl/pages/investigacion/concursos_internos.html

Universidad de Antofagasta (2016), Plan de Desarrollo Estratégico Institucional, (2016-2020) Visitado 14 de abril de 2016: http://intranetua.uantof.cl/ plan_desarrollo/documentos/avance/ PDE_V047.pdf 